\title{
Influence of the Radiation Dose to Salivary Glands on Xerostomia in Patients with Head and Neck Carcinomas
}

\author{
André Buchali*, Christina Schröder, Dietrich Sidow, Eyck Blank \\ Department of Radiation Oncology, Ruppiner Kliniken GmbH, Neuruppin, Germany. \\ Email: *a.buchali@ruppiner-kliniken.de
}

Received December $21^{\text {st }}, 2012$; revised January $23^{\text {rd }}, 2013$; accepted February $2^{\text {nd }}, 2013$

\begin{abstract}
Purpose: Investigation of the influence of radiation dose to salivary glands on xerostomia in patients with head and neck cancers. Methods: From October 2002 to December 2011, 548 patients with head and neck carcinomas were treated in our department using intensity modulated radiotherapy (IMRT). 325 patients were eligible for analysis more than 1 year after irradiation. Xerostomia was evaluated according to the criteria of Radiation Therapy and Oncology Group (RTOG) and xerostomia related questionnaire. For statistical analysis grade 1 and 2 were recorded as mild and grade 3 and 4 as severe xerostomia. The dosimetric values for absolute mean dose, biological equivalent mean dose (EQD2), the relative organ volume not exceeding $20 \mathrm{~Gy}, 25 \mathrm{~Gy}$ and $30 \mathrm{~Gy}$ (V20, V25, V30) for all 4 major salivary glands or for both parotid glands only were used for analysis. V20 revealed the best discrimination between both patient groups (with vs. without xerostomia), compared to parameters V25 and V30. Therefore the volume of the salivary glands receiving less than $20 \mathrm{~Gy}(\mathrm{~V}<20 \mathrm{~Gy})$ was analyzed additionally. Mann-Whitney-U-test, Kruskal-Wallis-test and logistic regression were used in statistical analysis. Results: A TD 50 can be determined for the occurrence of xerostomia more than one year after radiotherapy for both parotid glands of $19.3 \mathrm{~Gy}$ for the mean dose absolute, 11.2 Gy for the mean dose EQD2, 38.2\% for V20, 26.8\% for V25, 18.7\% for V30, $34.9 \mathrm{ml}$ for $\mathrm{V}<20$ Gy. For all major salivary glands theses values were $25.7 \mathrm{~Gy}$ for the mean dose absolute, $15.6 \mathrm{~Gy}$ for the mean dose EQD2, 51.3\% for V20, 41.1\% for V25, 33.9\% for V30 and $34.8 \mathrm{ml}$ for V $<20 \mathrm{~Gy}$. Conclusions: The identification of a tolerance dose for the salivary glands for treatment planning appears to be difficult, as the dose-response correlation only shows a flat slope. Additionally, a large interindividual variability seems to exist. We could not found any threshold dose for development of xerostomia.
\end{abstract}

Keywords: Xerostomia; Salivary Glands; Tolerance Dose; Irradiation

\section{Introduction}

Xerostomia is one of the most common radiation-induced side effects in patients with head and neck cancers, permanently impairing the quality of life of affected patients. Saliva has several functions, including a bactericidal effect in the oral cavity improving healing processes of mucosa lesions, the mechanical douche of food residues from the oral cavity, the regeneration of adamantine, and the neutralization of food acids. Thus, radiation induced xerostomia, with its reduction of saliva flow also leads to unwanted long-term effects.

The acute effect of irradiation to the secretory cells of the salivary glands most probably causes a selective damage of the plasma membrane, whereas the long term effect is probably due to classic mitotic cell death [1]. The influence of xerostomia on patients' quality of life is discussed controversially. A correlation between both the nonstimulated and stimulated salivary flow rates, and the

*Corresponding author. quality of life confirmed by xerostomia questionnaires was found [2-4].

On the other hand an improvement of quality of life scores was found when mucositis was recovering, although xerostomia was persisting [5]. Radiation dose clearly influences the production of saliva of both the large and the small salivary glands [6,7]. Blanco et al. found the strongest correlation between stimulated saliva flow and dose-volume parameters of the salivary glands, whereas cofactors (chemotherapy, age, general condition) only showed a modest influence [2].

The therapy of xerostomia after radiation therapy is difficult, which makes prevention essential. By modern treatment planning and radiation application techniques (3D treatment planning vs. conventional treatment planning, IMRT vs. 3D-CRT, 7-field vs. 5-field radiation) it was possible to reduce the dose to the salivary glands [3, 8-14]. Furthermore, it was attempted to reduce the salivary gland dose by modifying the target volume with preservation of the contralateral parotid and/or subman- 
dibular gland or lowering the cranial border of the target volume of level 2 of the cervical lymph nodes [15-17].

The aim of this paper was the investigation of the influence of radiation dose to salivary glands on xerostomia in patients with head and neck cancers.

\section{Methods and Materials}

From 7 October 2002 to 30 December 2011, 548 patients with head and neck carcinomas were treated in our department using intensity modulated radiotherapy (IMRT) with sliding windows ${ }^{\mathrm{TM}}$ technique and an integrated boost strategy. 325 patients were eligible for analysis. They underwent an irradiation of the primary tumor located in the naso-, oro-, hypopharynx, larynx or oral cavity, and supraclavicular lymph nodes and were available for a follow up examination more than one year after radiotherapy. Data after re-irradiation were not included.

Xerostomia was evaluated according to the acute radiation morbidity scoring criteria of Radiation Therapy and Oncology Group (RTOG) [18] and xerostomia related questionnaire.

At the time of therapy the median age of patients was 58 years (range: 30 - 84 years). From those 223 patients, missing the follow up examination more than one year after radiotherapy, 155 patients had died and 68 patients didn't appear. The median follow up of the patients included into this study was 34.7 months (range: 12 - 119.1 months). Primary tumor localizations, tumor stages and lymph node status of patients are shown in Tables $\mathbf{1}$ and 2.

64 patients were treated by a definitive radiotherapy, 173 patients were irradiated after a complete resection (R0), 57 patients after a resection with microscopic involved margins (R1) and 31 patients after a resection with a macroscopic residue ( $\mathrm{R} 2)$.

The macroscopic tumor manifestations (primary tumor, lymph node metastases) were irradiated with a single dose of 2 Gy, 6 times per week up to a total dose of 72 Gy. A total dose of 64 Gy was used for the tumor bed

Table 1. Primary tumor localizations $(n=325)$.

\begin{tabular}{lcc}
\hline Primary tumor localization & $\mathrm{n}$ & $(\%)$ \\
\hline oropharynx & 125 & $(38.5 \%)$ \\
tongue/floor of the mouth & 51 & $(15.7 \%)$ \\
larynx & 46 & $(14.2 \%)$ \\
hypopharynx & 43 & $(13.2 \%)$ \\
CuP & 22 & $(6.8 \%)$ \\
nasopharynx & 16 & $(4.9 \%)$ \\
paranasal sinus & 8 & $(2.5 \%)$ \\
others & 14 & $(4.2 \%)$ \\
\hline
\end{tabular}

Table 2. $T$ - and $N$ - statuses of the patients $(n=325)$.

\begin{tabular}{|c|c|c|c|c|}
\hline TStage N-Stage & N0 & N1 & $\mathrm{N} 2$ & N3 \\
\hline $\mathrm{Tx}$ & 0 & 2 & 19 & 2 \\
\hline $\mathrm{T} 1$ & 8 & 8 & 28 & 1 \\
\hline $\mathrm{T} 2$ & 35 & 11 & 66 & 2 \\
\hline T3 & 12 & 5 & 47 & 4 \\
\hline $\mathrm{T} 4$ & 15 & 3 & 52 & 5 \\
\hline
\end{tabular}

after R1-resection or for the affected lymph nodes in case of perinodal lymph node infiltration after neck dissection. A total dose of 56 Gy was applied for the tumor bed after a R0-resection or to the affected lymph nodes in case of a non-perinodal lymph node infiltration after neck dissection. 99 patients were irradiated with a total dose of 72 Gy, 131 patients with 64 Gy, 93 patients with 56 Gy and 2 patients received different radiation dose.

Until 6 October 2003 the treatment planning system CADPLANTM (Firma Varian Medical Systems) $(\mathrm{n}=16)$ and since 7 October 2003 the treatment planning system Eclipse $^{\mathrm{TM}}$ (Firma Varian Medical Systems) $(\mathrm{n}=309)$ has been used. Mann-Whitney-U-test, Kruskal-Wallis-test and logistic regression were used in statistical analysis to assess the effect of dose-volume related factors. During treatment planning both submandibular and parotid glands were selectively contoured.

\section{Results}

The volume of both parotid glands and submandibular glands amounted to $49.4 \mathrm{ml} \pm 16.9 \mathrm{ml}$ (mean $\pm \mathrm{SD}$ ) and $15.0 \mathrm{ml} \pm 5.3 \mathrm{ml}$, respectively. The number of patients without, mild or moderate xerostomia at the end of irradiation, after 3 months and more than one year after radiotherapy are listed in Table 3. Because of the small numbers of patients with a moderate (II) xerostomia, patients were summed up into 2 groups only for further analysis: with or without xerostomia. The dosimetric values for absolute mean dose, biological equivalent mean dose (EQD2), the relative organ volume not exceeding 20 Gy, 25 Gy and 30 Gy (V20, V25, V30) for all 4 Salivary glands or for both parotid glands only were used for analysis. V20 revealed the best discrimination between both patient groups (with vs. without xerostomia), compared to parameters V25 and V30. Therefore the volume of the salivary glands receiving less than $20 \mathrm{~Gy}(\mathrm{~V}<20$ Gy) was analysed additionally. The data are shown in Tables 4 and 5.

The probability of the occurrence of xerostomia more than one year after radiotherapy was analysed by logistic regression as a function of dose parameters. Results are shown in Table 5 and demonstrated in Figures $\mathbf{1}$ and 2. 
Table 3. Xerostomia of patients after radiotherapy $(\mathrm{RT})(\mathrm{n}=325)$.

\begin{tabular}{|c|c|c|c|}
\hline xerostomia & End of RT & 3 months after RT & $>1$ year after $\mathrm{RT}$ \\
\hline $\operatorname{absent}\left(0^{\circ}\right)$ & $185(56.9 \%)$ & $132(40.6 \%)$ & $157(48.3 \%)$ \\
\hline $\operatorname{mild}\left(\mathrm{I}^{\circ}\right)$ & $113(34.8 \%)$ & $147(45.2 \%)$ & $140(43.1 \%)$ \\
\hline moderate $\left(\mathrm{II}^{\circ}\right)$ & $27(8.3 \%)$ & $46(14.2 \%)$ & $28(8.6 \%)$ \\
\hline
\end{tabular}

Table 4. Dose and volume parameters of salivary glands (mean \pm SD).

\begin{tabular}{|c|c|c|c|c|c|c|c|}
\hline & volume & \multicolumn{2}{|c|}{ mean dose } & V20 & V25 & V30 & $\mathrm{V}<20 \mathrm{~Gy}$ \\
\hline & & absolute & EQD2 & & & & \\
\hline & $(\mathrm{ml})$ & (Gy) & (Gy) & $(\%)$ & $(\%)$ & $(\%)$ & (ml) \\
\hline Parotid right & $24 \pm 9$ & $21 \pm 11$ & $13 \pm 8$ & $42 \pm 24$ & $31 \pm 22$ & $24 \pm 21$ & $14 \pm 8$ \\
\hline Parotid left & $25 \pm 9$ & $22 \pm 12$ & $13 \pm 9$ & $42 \pm 25$ & $32 \pm 24$ & $26 \pm 22$ & $15 \pm 9$ \\
\hline Submand. right & $8 \pm 3$ & $50 \pm 15$ & $36 \pm 12$ & $95 \pm 18$ & $90 \pm 22$ & $85 \pm 26$ & $0,3 \pm 1$ \\
\hline Submand. left & $7 \pm 3$ & $51 \pm 15$ & $36 \pm 12$ & $95 \pm 16$ & $90 \pm 22$ & $85 \pm 26$ & $0,4 \pm 1$ \\
\hline
\end{tabular}

Table 5. Dose and volume parameters of salivary glands with respect to xerostomia (mean \pm SD).

\begin{tabular}{|c|c|c|c|c|}
\hline & & Xerostomia: No & Xerostomia: Yes & $\mathrm{p}$-value \\
\hline \multicolumn{5}{|c|}{ Parotid glands } \\
\hline mean dose absolute & (Gy) & $20.1 \pm 9.3$ & $22.7 \pm 9.2$ & 0.001 \\
\hline mean dose EQD2 & (Gy) & $11.9 \pm 6.4$ & $13,7 \pm 6.5$ & 0.001 \\
\hline $\mathrm{V} 20$ & $(\%)$ & $38.5 \pm 21.4$ & $45.1 \pm 22.0$ & 0.001 \\
\hline V25 & $(\%)$ & $29.1 \pm 19.3$ & $33.7 \pm 19.7$ & 0.003 \\
\hline V30 & $(\%)$ & $23.2 \pm 18.2$ & $26.5 \pm 18.3$ & 0.008 \\
\hline $\mathrm{V}<20 \mathrm{~Gy}$ & $(\mathrm{ml})$ & $30.8 \pm 15.5$ & $27.6 \pm 15.1$ & 0.043 \\
\hline \multicolumn{5}{|l|}{4 major salivary glands } \\
\hline mean dose absolute & (Gy) & $27.2 \pm 8.7$ & $29.2 \pm 8.4$ & 0.011 \\
\hline mean dose EQD2 & (Gy) & $16.7 \pm 6.3$ & $18.2 \pm 6.1$ & 0.007 \\
\hline V20 & $(\%)$ & $51.6 \pm 17.5$ & $56.9 \pm 17.7$ & 0.002 \\
\hline $\mathrm{V} 25$ & $(\%)$ & $43.0 \pm 16.3$ & $47.2 \pm 16.3$ & 0.004 \\
\hline V30 & $(\%)$ & $37.3 \pm 16.1$ & $40.6 \pm 15.9$ & 0.021 \\
\hline $\mathrm{V}<20 \mathrm{~Gy}$ & $(\mathrm{ml})$ & $31.7 \pm 15.7$ & $28.3 \pm 15.5$ & 0.029 \\
\hline
\end{tabular}

From these graphs a TD 50 can be determined for the occurrence of xerostomia more than one year after radiotherapy for both parotid glands of 19.3 Gy for the mean dose absolute, 11.2 Gy for the mean dose EQD2, $38.3 \%$ for $\mathrm{V} 20,26.8 \%$ for $\mathrm{V} 25,18.7 \%$ for $\mathrm{V} 30$ and 34.9 $\mathrm{ml}$ for $\mathrm{V}<20 \mathrm{~Gy}$. For all major salivary glands theses values were 25.7 Gy for the mean dose absolute, 15.6 Gy for the mean dose EQD2, 51.3\% for V20, 41.1\% for V25, $33.9 \%$ for $\mathrm{V} 30$ and $34.8 \mathrm{ml}$ for $\mathrm{V}<20 \mathrm{~Gy}$.

\section{Discussion}

\subsection{Finding the Tolerance Dose}

The identification of a tolerance dose for the salivary glands for treatment planning appears to be difficult, as the dose-response correlation only shows a flat slope. Additionally, a large interindividual variability seems to exist [19]. The threshold dose for development of xerostomia was described before in the range of 10 to 25.8 

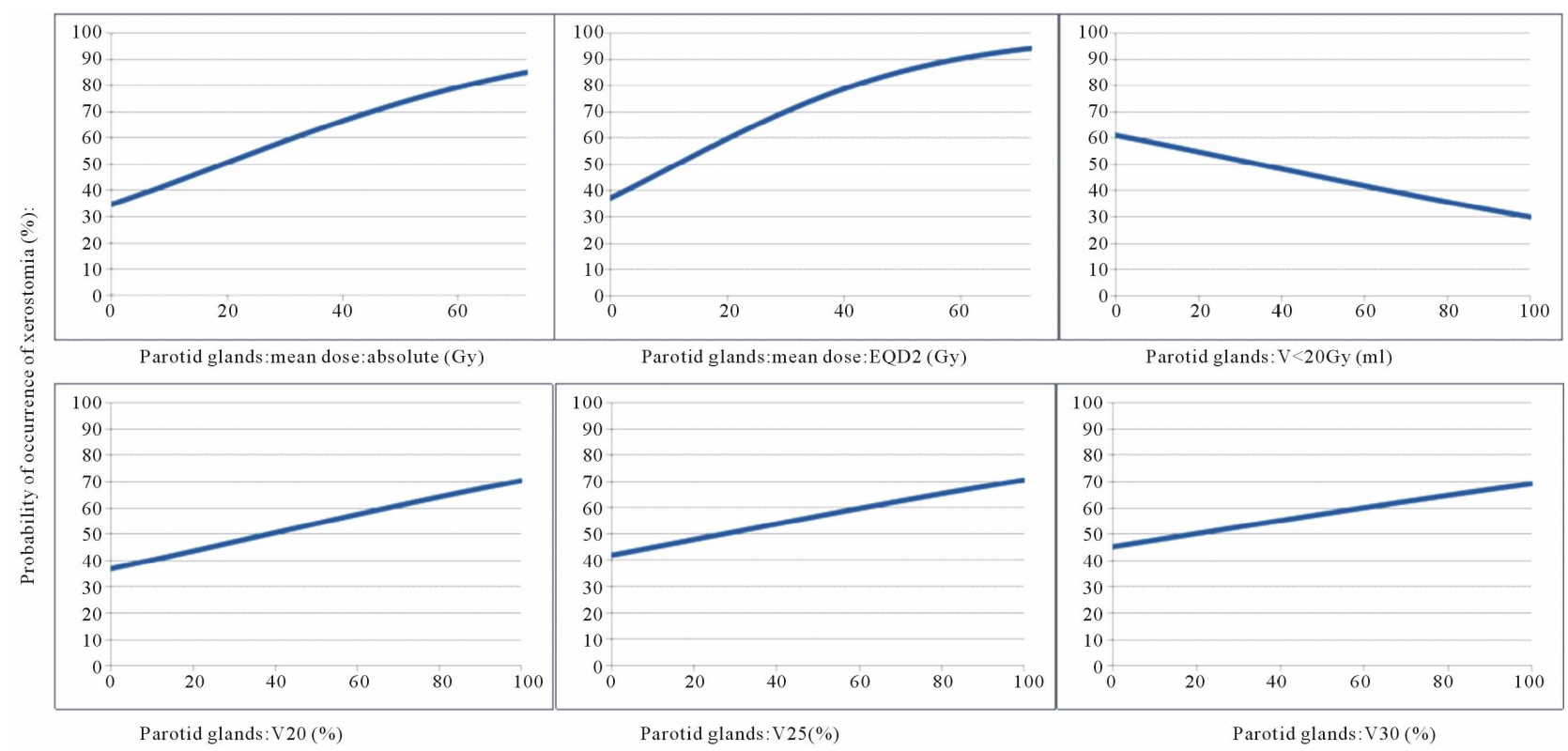

Figure 1. Probability of occurrence of xerostomia (\%) as a function of the dose parameters of the parotid glands.
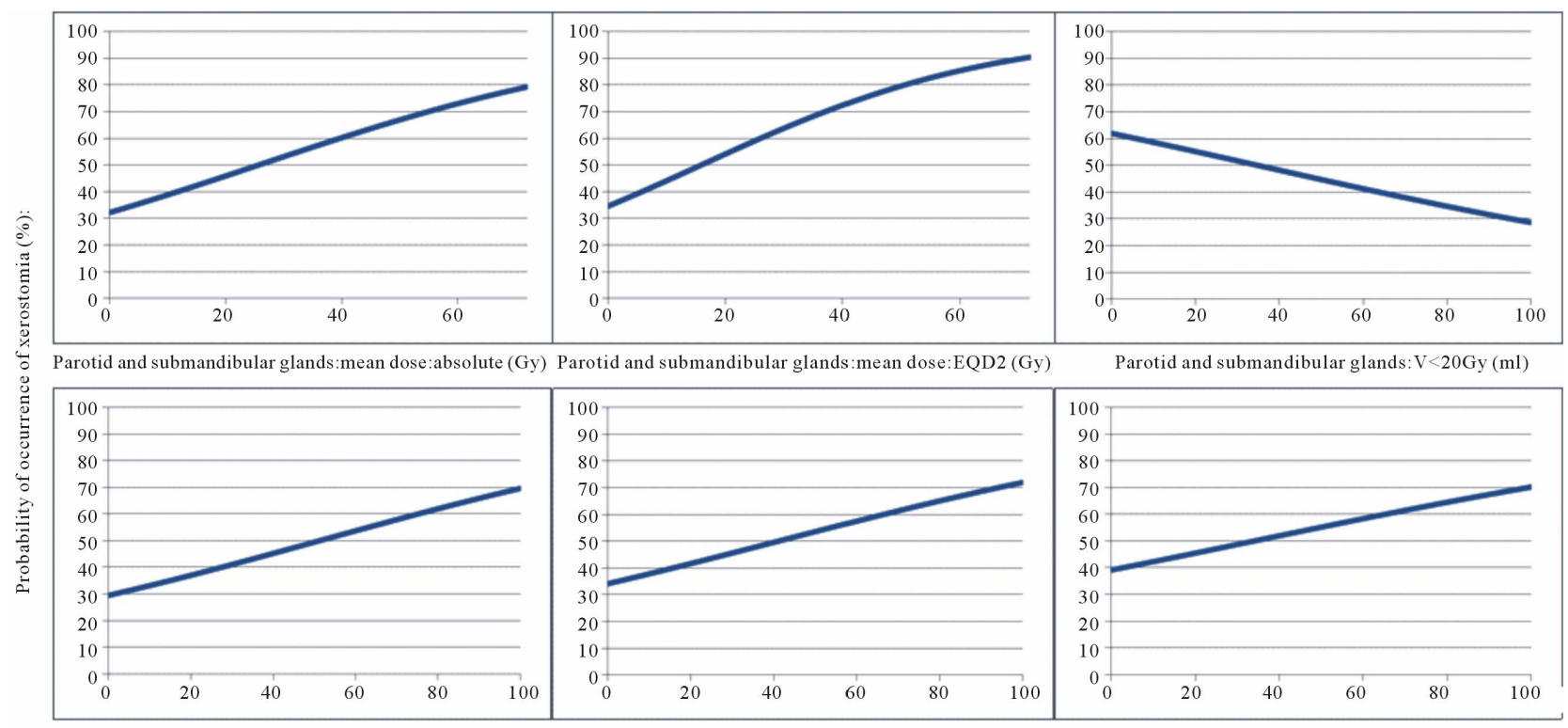

Parotid and submandibular glands:V20 (\%)

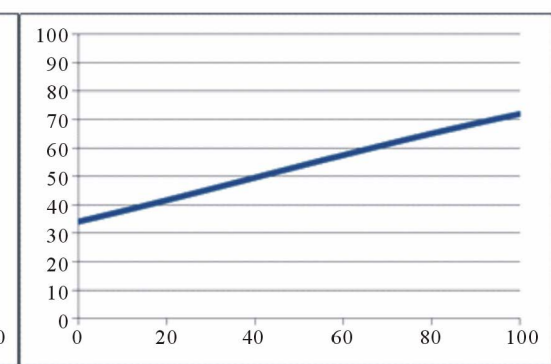

Parotid and submandibular glands:V25(\%)
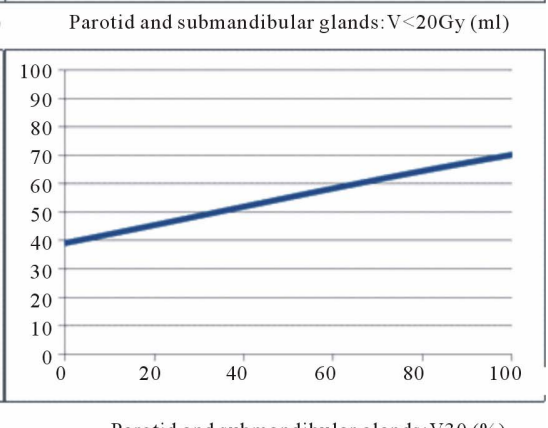

Parotid and submandibular glands:V30 (\%)

Figure 2. Probability of occurrence of xerostomia (\%) as a function of the dose parameters of the 4 major salivary glands.

Gy. These dose values refer to either both parotid glands as a sum or to the so called contralateral parotid gland [2,15,19-24].

For TD 50 one year after irradiation, dose values for the parotid glands range between $30 \mathrm{~Gy}$ and 43 Gy [7]. In our own analysis the TD 50 of the mean dose amounts to absolute $19.3 \mathrm{~Gy}$ and appears markedly lower.

\subsection{Biological Effective Dose}

The biological effectiveness of the mean dose depends on the total dose applied and has generally not been con- verted to the equivalent dose for a fractionated dose of 2 Gy (EQD2). Therefore, in our own patient population receiving total doses between 56 and 72 Gy not only the mean dose but also the V20, V25 and V30 show a moderate different biological effectiveness, assuming a probably low $\alpha / \beta$ value of the salivary gland tissue. Furthermore, a TD 50 for the EQD2 of only 11.2 Gy demonstrates a high radiosensitivity.

\section{Contouring}

We selectively contoured each of the 4 major salivary 
glands during treatment planning. Some authors describe a selective preservation of the contralateral salivary glands. In case of a large, central tumor (e.g. larynx or hypopharynx carcinoma) or an N2c situation it appears difficult to define which of the salivary glands is the contralateral one and therefore should be preserved selectively. As the consequence we used the total volume of the salivary glands for our analysis.

\subsection{Submandibular Glands}

Without stimulation the submandibular glands produce most of saliva [25]. The authors were able to prove that patients whose contralateral submandibular gland was spared reported less high grade xerostomia. However, in our own patient population submandibular glands were resected bilaterally in 30 patients $(9.2 \%)$ and unilaterally in further 54 patients $(16.6 \%)$. This surgical intervention may have influenced the occurrence of xerostomia.

\subsection{Recovery of Salivary Glands}

Salivary glands may show a recovery from the reduction of saliva production, which appears most likely between 3 months and 1 year after radiotherapy [2,7,8,26-28]. The recovery is reported after doses up to 39 Gy [29]. Eventually a recovery effect develops even later on $[26,30]$. In The data of our population do not represent any effect of recovery.

\subsection{Differences between Clinical Studies}

The influence of xerostomia on patients' quality of life is not completely certain [2-4]. Furthermore, the flow rates of the major salivary glands correlate only weakly with the xerostomia of the patients [30]. An increased xerostomia score may also be influenced by a preexisting xerostomia [30]. We did not analyze this problem directly, but it may be assumed to exist from dose effect curves (Figures 1 and 2) Besides, initial xerostomia rather exerts a similar kinetic as a consequential late effect of an acute injury, whereas late xerostomia is a "true" long term effect [31]. As a consequence, acute and late xerostomia probably may show different tolerance doses [32].

Also, most studies have different clinical endpoints: the occurrence of xerostomia, the occurrence of xerostomia $\geq$ III or the reduction of the stimulated and/or unstimulated salivary flows. In this analysis, the occurrence of xerostomia was defined as the endpoint without referring to a reduction of stimulated and/or unstimulated salivary flow.

In our own analysis a TD 50 for the parotid glands and all major salivary glands respectively could be defined with respect to our specific treatment planning parameters. It is valid for the question of occurrence vs. avoidance of xerostomia only. The defined tolerance doses are applicable for our department's concept of preservation dealing with the entire tissue of the 4 major salivary glands.

\section{REFERENCES}

[1] A. W. Konings, R. P. Coppes and A. Vissink, "On the Mechanism of Salivary Gland Radiosensitivity," International Journal of Radiation Oncology, Biology, Physics, Vol. 62, No. 4, 2005, pp. 1187-1194. doi:10.1016/j.ijrobp.2004.12.051

[2] A. I. Blanco, K. S. C. Chao, I. El Naqa, G. E. Franklin, K. Zakarian, M. Vicic and J. O. Deasy, "Dose-Volume Modeling of Salivary Function in Patients with of Head-andNeck Cancer Receiving Radiotherapy," International Journal of Radiation Oncology, Biology, Physics, Vol. 62, No. 4, 2005, pp. 1055-1069. doi:10.1016/j.ijrobp.2004.12.076

[3] K. S. C. Chao, J. O. Deasy, J. Markmann, J. Haynie, C. A. Perez, J. A. Purdy and D. A. Lowe, "A Prospective Study of Salivary Function Sparing in Patients with Head-andNeck Cancers Receiving Intensity-Modulated or ThreeDimensional Radiation Therapy: Initial Results," International Journal of Radiation Oncology, Biology, Physics, Vol. 49, No. 4, 2001, pp. 907-916. doi:10.1016/S0360-3016(00)01441-3

[4] A. Meirovitz, C. A. Murdoch-Kinch, M. Schipper, C. Pan and A. Eisbruch, "Grading Xerostomia by Physicians or by Patients after Intensity-Modulated Radiotherapy of Head-and-Neck Cancer," International Journal of Radiation Oncology, Biology, Physics, Vol. 66, No. 2, 2006, pp. 445-453. doi:10.1016/j.ijrobp.2006.05.002

[5] J. Ringash, P. Warde, G. Lockwood, M. Math, B. O'Sullivan, J. Waldron and B. Cummings, "Posttherapy Quality of Life for Head and Neck Cancer Patients is Independent of Xerostomia," International Journal of Radiation Oncology, Biology, Physics, Vol. 61, No. 5, 2005, pp. 1403-1407. doi:10.1016/j.ijrobp.2004.08.001

[6] M. B. Parliament, R. A. Scrimger, S. G. Anderson, E. Kurien, H. K. Thompson, G. C. Field and J. H. Hanson, "Preservation of Oral Health-Related Quality of Life and Salivary Flow Rates after Inverse-Planned Intensitiy-Modulated Radiotherapy (IMRT) for Head and Neck Cancer," International Journal of Radiation Oncology, Biology, Physics, Vol. 58, No. 3, 2004, pp. 663-673. doi:10.1016/S0360-3016(03)01571-2

[7] J. M. Roesink, M. A. Moerland, A. Hoekstra, P. P. van Rijk and H. J. Terhaard, "Scintigraphic Assessment of Early and Late Parotid Gland Function after Radiotherapy for Head-and-Neck Cancer: A Prospective Study of DoseVolume Response Relationships," International Journal of Radiation Oncology, Biology, Physics, Vol. 58, No. 5, 2004, pp. 1451-1460. doi:10.1016/j.ijrobp.2003.09.021

[8] P. M. Braam, C. P. Raaijmakers, J. M. Roesink and C. Terhaard, "Intensity-Modulated Radiotherapy Reduces Long-Term Parotid Gland Function Complications Compared with Conventional Radiotherapy," Radiotherapy \& Oncology, Vol. 82, Suppl. 1, 2007, p. 14. doi:10.1016/S0167-8140(07)80047-8 
[9] T. Kuhnt, N. Jirsak, A. C. Müller, T. Pelz, C. Gernhardt, H. G. Schaller, M. Janich, R. Gerlach and J. Dunst, "Quantitative and Qualitative Investigations of Salivary Gland Function in Dependence on Irradiation Dose and Volume for Reduction of Xerostomia in Patients with Head-and-Neck Cancer," Strahlentherapie und Onkologie, Vol. 181, No. 8, 2005, pp. 520-528. doi:10.1007/s00066-005-1366-y

[10] A. Buchali, E. Blank, D. Sidow, M. Schmidt and W. Huhnt, "Dose to Salivary Glands in the Treatment of 36 Head and Neck Cancer Patients Using Intensity Modulated Radiotherapy," Strahlentherapie und Onkologie, Vol. 180, Suppl. 1, 2004, p. 45.

[11] E. H. N. Pow, D. L. W. Kwong, A. S. McMillan, M. C. M. Wong, J. S. T. Sham, L. H. T. Leung and W. K. Leung, "Xerostomia and Quality of Life after Intensity-Modulated Radiotherapy vs. Conventional Radiotherapy for Early Stage Nasopharyngeal Carcinoma: Initial Report on a Randomized Controlled Clinical Trial," International Journal of Radiation Oncology, Biology, Physics, Vol. 66, No. 4, 2006, pp. 981-991. doi:10.1016/j.ijrobp.2006.06.013

[12] M. Braaksma, O. B. Wijers, J. R. Sörnsen van de Koste, H. van der Est, P. I. M. Schmitz, P. J. C. M. Nowak and P. C. Levendag, "Optimization of Conformal Radiation Therapy by Intensity Modulation: Cancer of the Larynx and Salivary Gland Function," Radiotherapy \& Oncology, Vol. 66, No. 3, 2003, pp. 291-302. doi:10.1016/S0167-8140(03)00038-0

[13] L. Marucci, S. Marzi, I. Sperduti, G. Giovinazzo, P. Pinnaro, M. Benassi and L. Strigari, "Influence of IntensityModulated Radiation Therapy Technique on Xerostomia and Related Quality of Life in Patients Treated with Intensity-Modulated Radiation Therapy for Nasopharyngeal Cancer," Head Neck, Vol. 34, No. 3, 2011, pp. 328-335.

[14] P. Dirix, S. Nuyts and W. van den Bogaert, "RadiationInduced Xerostomia in Patients with Head and Neck Cancer," Cancer, Vol. 107, No. 11, 2006, pp. 2525-2534. doi:10.1002/cncr.22302

[15] A. Maes, C. Weltens, P. Flamen, P. Lambin, R. Bogaerts, X. Liu, J. Baetens, R. Hermans and W. van den Bogaert, "Preservation of Parotid Function with Uncomplicated Conformal Radiotherapy," Radiotherapy \& Oncology, Vol. 63, No. 2, 2002, pp. 203-211. doi:10.1016/S0167-8140(02)00013-0

[16] E. Astreinidou, H. Dehnad, C. H. Terhaard and C. P. Raaijmakers, "Level II Lymph Nodes and RadiotherapyInduced Xerostomia," International Journal of Radiation Oncology, Biology, Physics, Vol. 58, No. 1, 2004, pp. 124-131. doi:10.1016/S0360-3016(03)01391-9

[17] Z. H. Wang, C. Yan, Z. Y. Zhang, C. P. Zhang, H. S. Hu, W. Y. Tu and J. Kirwan, "Impact of Salivary Gland Dosimetry on Post-IMRT Recovery of Saliva Output and Xerostomia Grade for Head-and-Neck Cancer Patients Treated with or without Contralateral Submandibular Gland Sparing: A Longitudinal Study," International Journal of Radiation Oncology, Biology, Physics, Vol. 81, No. 5, 2011, pp. 1479-1487. doi:10.1016/j.ijrobp.2010.07.1990

[18] Radiation Therapy and Oncology Group: www.rtog.org/
ResarchAssociates/ AdverseEventReporting/ AcuteRadiationMorbidityScoringCriteria.aspx

[19] A. Buchali, S. Esser-Naumann, D. Sidow and E. Blank, "Dose to Salivary Glands and Xerostomia in 226 Head and Neck Cancer Patients Treated with Intensity Modulated Radiotherapy," Strahlentherapie und Onkologie, Vol. 184, Suppl. 1, 2008, p. 18.

[20] V. Moiseenko, J. Wu, A. Hovan, Z. Saleh, A. Apte, J. O. Deasy, S. Harrow, C. Rabuka, A. Muggli and A. Thompson, "Treatment Planning Constraints to Avoid Xerostomia in Head-And-Neck Radiotherapy: An Independent Test of QUANTEC Criteria Using a Prospectively Collected Dataset," International Journal of Radiation Oncology, Biology, Physics, Vol. 82, No. 3, 2011, pp. 11081114. doi:10.1016/i.ijrobp.2011.04.020

[21] J. O. Deasy, V. Moiseenko, L. Marks, C. Chao, J. Nam and A. Eisbruch, "Radiotherapy Dose-Volume Effects on Salivary Gland Function," International Journal of Radiation Oncology, Biology, Physics, Vol. 76, No. 3, 2010, pp. 58-63. doi:10.1016/j.ijrobp.2009.06.090

[22] M. W. Muenter, C. P. Karger, S. G. Hoffner, H. Hof, C. Thilmann, V. Rudat, S. Nill, M. Wannenmacher and J. Debus, "Evaluation of Salivary Gland Function after Treatment of Head-And-Neck Tumors with IntensityModulated Radiotherapy by Quantitative Pertechnetate Scintigraphy," International Journal of Radiation Oncology, Biology, Physics, Vol. 58, No. 1, 2007, pp. 175184.doi:10.1016/S0360-3016(03)01437-8

[23] A. P. Jellema, P. Doornaert, B. J. Slotman, C. R. Leemans and J. A. Langendijk, "Does Radiation Dose to the Salivary Glands and Oral Cavity Predict Patient-Rated Xerostomia and Sticky Saliva in Head and Neck Cancer Patients Treated with Curative Radiotherapy?" Radiotherapy \& Oncology, Vol. 77, No. 2, 2005, pp. 164-171. doi:10.1016/j.radonc.2005.10.002

[24] B. Bussels, A. Maes, P. Flamen, P. Lambin, K. Erven, R. Hermans, S. Nuyts, C. Weltens, S. Cecere, E. Lesaffre and W. van der Bogaert, "Dose-Response Relationships within the Parotid Gland after Radiotherapy for Head and Neck Cancer," Radiotherapy \& Oncology, Vol. 73, No. 3, 2004, pp. 297-306. doi:10.1016/j.radonc.2004.09.015

[25] K. Saarilahti, M. Kouri, J. Collan, A. Kangasmäki, T. Atula, H. Joensuu and M. Tenhunen, "Sparing of the Submandibular Glands by Intensity Modulated Radiotherapy in the Treatment of Head and Neck Cancer," $R a$ diotherapy \& Oncology, Vol. 78, No. 3, 2006, pp. 270275. doi:10.1016/i.radonc.2006.02.017

[26] C. Ortholan, E. Chamorey, K. Benezery, J. Thariat, O. Dassonville, G. Poissonet, A. Bozec, P. Follana, F. Peyrade A. Sudaka, J. P. Gerard and R. J. Bensadoun, "Modeling of Salivary Production Recovery after Radiotherapy Using Mixed Models: Determination of Optimal Dose Constraint for IMRT Planning and Construction of Convenient Tools to Predict Salivary Function," International Journal of Radiation Oncology, Biology, Physics, Vol. 73, No. 1, 2009, pp. 178-186. doi:10.1016/j.ijrobp.2008.03.068

[27] S. Jabbari, H. M. Kim, M. Feng, A. Lin, C. Tsien, M. Elshaikh, E. Terrel, C. Murdoch-Kinch and A. Eisbruch, 
"Quality of Life and Xerostomia Following Standard vs. Intensity Modulated Irradiation: A Matched Case-Control Comparison," International Journal of Radiation Oncology, Biology, Physics, Vol. 63, No. 3, 2005, pp. 725-731. doi:10.1016/j.ijrobp.2005.02.045

[28] Y. Li, J. Taylor, R. Ten Haken and A. Eisbruch, "The Impact of Dose on Parotid Salivary Recovery in Head and Neck Cancer Patients Treated with Radiation Therapy," International Journal of Radiation Oncology, Biology, Physicss, Vol. 67, No. 3, 2007, pp. 660-669.

[29] C. A. Murdoch-Kinch, H. M. Kim, K. A. Vineberg, J. A. Ship and A. Eisbruch, "Dose-Effect Relationships for the Submandibular Salivary Glands and Implications for Their Sparing by Intensity Modulated Radiotherapy," International Journal of Radiation Oncology, Biology, Physics, Vol. 72, No. 2, 2008, pp. 373-382. doi:10.1016/j.ijrobp.2007.12.033

[30] A. Eisbruch, K. M. Kim, J. E. Terrell, L. H. Marsh, L. A.
Dawson and J. A. Ship, "Xerostomia and Its Predictors Following Parotid Sparing Irradiation of Head-And-Neck Cancer," International Journal of Radiation Oncology, Biology, Physics, Vol. 50, No. 3, 2001, pp. 695-704. doi:10.1016/S0360-3016(01)01512-7

[31] H. Jung, H. P. Beck-Bornholdt, V. Svoboda, W. Alberti and T. Herrmann, "Quantification of Late Complications after Radiation Therapy," Radiotherapy \& Oncology, Vol. 61, No. 3, 2001, pp. 233-224. doi:10.1016/S0167-8140(01)00457-1

[32] S. Marzi, P. Pinnaro, D. D’Alessio, L. Strigari, V. Bruzzaniti, C. Giordano, G. Giovinazzo and L. Marucci, "Anatomical and Dose Changes of Gross Tumor Volume and Parotid Glands for Head and Neck Cancer Patients during Intensity-Modulated Radiotherapy: Effect on the Probability of Xerostomia Incidence," Journal of Clinical Oncology, Vol. 24, No. 3, 2011, pp. 1-9. 